\title{
1. Civil society, citizenship and activism: conditions for real democracy
}

Solidarity, empowerment, tolerance and trust in others depend on a society's ability to include people by providing opportunities for citizens to be involved in all types of institutions. Social inclusion or cohesion has to transcend social, ethnic and gender differences, and is conditional on institutions and organizations acknowledging everybody and treating all citizens equally, as well as on the ability to establish and maintain trust and civility between different groups of citizens. 'To maintain democracy, and to achieve justice, it is often necessary for the civil to "invade" noncivil spheres, to demand certain kinds of reforms, and to monitor them through regulation in turn' (Alexander 2006: 34). It is in this respect essential that ordinary people, in their daily lives, display tolerance and good citizenship by adapting their personal interests, being helpful, seeking compromise and being open and pleasant to others. In other words, civility - at individual, group, regional and national levels - is one of the foundations of an open and democratic society in which everybody plays a role on equal terms. We need what Alexander (2006) calls a 'civil sphere of justice' to ensure democracy and social justice, a sphere characterized by universality and inclusiveness, and with collective obligations that at the same time protect the individual autonomy of citizens. In a real democratic society, collectivism and individualism are practiced simultaneously, but this can only be the case if civility, justice and mutual dialogue dominate civil actions.

Civility, trust and equality are particularly crucial in dialogue in the public sphere with people we do not know personally. This is also a prerequisite for an inclusive political democracy and an open democratic culture, one in which ordinary people engage with what they consider to be the big issues. However, civility is not just about kindness, understanding and compromise. Those who take part in public debates must also be prepared to accept conflicting interests and differing attitudes to critical questions facing society as a whole. In this sense, civility underlines the importance of diversity, disagreement and resistance in interpersonal relationships as well as in socio-political dialogue. In other words civility represents:

civic virtues such as tolerance, non-discrimination and public reasonableness. Civility is therefore 'more' than good manners - it is a set of practices that involves the exercise of self-constraint and a concern for others. It is expressed as a mode of 
conduct organized by reason and principle that allows one to negotiate differences in civil society fairly and reasonably. (White 2006: 446)

Civility is a core dimension for most social scientists in their understanding of civil society and its importance for democracy and social justice. Most definitions of civility agree that it serves as a test of civic competence because it requires citizens to exercise discipline, show concern for others, show tolerance and maintain a respectful and mutual dialogue in communication with fellow citizens - even on conflictual themes. Civility, however, does not need to be restricted to the civil sphere. It should be a principle for dialogue and behaviour in all social spheres.

Prerequisites for being a 'good' citizen are conditional on the individual having the economic, social and cultural resources to take part in public discourse, and showing tolerance and civility towards others in debates and when making decisions on matters of general concern. Just as important for civility is that society's institutions and organizations involve and acknowledge everybody equally in the democratic processes that lead to decisions on matters of general interest. In building this type of society, the three key concepts covered in this book are crucial: civil society, citizenship and active participation. This chapter discusses how these three concepts are understood in the book, elaborates on the importance of the concepts in implementation of civility and democracy, and discusses their mutual relations. The chapter concludes with a discussion of new forms of active participation and how late-modern activism has influenced the perception of civil society and citizenship.

\section{CIVIL SOCIETY}

Civil society denotes the public social sphere in which citizens engage in various types of communicative dialogue. These dialogues have many different forms. On the one hand, we have dialogues characterized by actions that are non-violent, seek compromise and strive for consensus around conflicts of interest. In principle, internal dialogue in the institutions and organizations that make up this type of civil society should help to socialize citizens by inculcating the values of democracy, citizenship and tolerance. Civil society thus provides space for what Walzer (1998: 134) characterizes as 'un-coerced human association between the individual and the state, in which people undertake collective action for normative and substantive purposes, relatively independent of government and the market' (cited from Edwards 2013: 4). More precisely, the civil society comprises a variety of democratically structured and emancipatory institutions that provide space for communicative interaction between citizens and ensure that participative, democratic dialogue is the dominant principle in the development of society. 
On the other hand, we also have communicative dialogues that are conflictual, dominant and exclusive, and dialogues that are limited to particular social groups or asymmetric in some other way. When Granovetter (1985) writes about strong and weak ties in social networks, it is precisely to emphasize that everyone is part of a wide range of different social relationships. Some are strong in the sense that the members of the network are closely linked to each other and cut off from other people: lodges, clubs, and so on. Other people are kept out and certain qualities are required to be part of the network. On the other hand, in a wide range of weak social relationships, ties are temporary, and transient in terms of intensity and content. These types of social network are wide and open, including co-operatives, professional networks and the like. The same applies to civil society organizations. Virtually all of them have criteria for membership and affiliation, which at the same time include some social groups and cut them off from others, which are thus excluded from the collective.

Civil society bears within it both a civilized and an uncivilized dimension. This applies on both personal and societal levels. Throughout most of his writings, and most clearly in the book Modernity and the Holocaust, Zygmunt Bauman (1989) has methodically explained how civilization and barbarism are two sides of the same coin, as witnessed in the many and varied wars and conflicts at any given time that involve these same 'civilized' Western democracies. The distinction between civilized and uncivilized is determined by who controls the apparatus of political power and how it is used. Regarding contemporary society, immanent tendencies towards domination and violence abound everywhere in civil society. Religious groups oppress non-believers, political parties advocate the use of force against those who think differently, civil society organizations institute discriminatory guidelines to determine who is included in and excluded from membership of the community. There are countless examples of uncivilized organizations that can be considered part of civil society but are exclusive and in many cases directly aggressive towards social groups that think differently.

Civil society is thus a community in which the individuals - and this concerns all, irrespective of race, gender, age or status - can practice civility, criticism and mutual acceptance. The ultimate test for civility in civil society organizations is that they are able to combine dialogue, solidarity and emancipation. This understanding of civil society is closely related to the idea of democracy as deliberative, with the citizens playing an active role and their critical reflections in the public political sphere being fundamental to the democratic process. 
In most analyses of civil society and its performance, it is conceptualized as an independent sphere with its own values, ethics and institutions:

But the civil sphere is not separated and ideal; it must exist in the real world. It must be located in time and space. As civil society settles down into everyday social systems, its contradictions become apparent. Real civil societies are created by social actors at a particular time and in a particular place. (Alexander 2006: 6)

There is a close connection and interdependence between the civil sphere and the other social spheres: state, corporate economy, religion, family, and so on. These other spheres have influence on the civil sphere through their structural composition, power relations and hierarchical organizations. Consequently, solidarity and civility in civil life depend on the interrelations between the different social spheres; here, the possibilities for the civil sphere, with its values and relations, to intermingle with the other social spheres are extremely important for the potential civil repair of everyday life in work, family and policy.

When it comes to how the civil sphere intervenes in the other social spheres, social movements and associations play a very important role. Social movements are typically founded on an idealistic purpose, dependent on the communication of values and in most cases anchored in special social groups, but 'this reflects the duality of social position in complex social systems and fragmented civil spheres. The civil rights and feminist movements were not only about the particular interests of racial and about gender groups. They were about the reconstruction of social solidarity, about its expansion and repair' (Alexander 2006: 7).

In this sense, civil society represents a battleground where a multiplicity of life-world positions and interests converge in public debate. In other words, the civil sphere is not restricted to any special types of institutions or associations, but must pervade all societal institutions; only then can we talk about a deliberative democracy. Between the civil sphere and the other social spheres, there is an open and historically indeterminate relation.

\section{Civil Society: Sector or Activity}

If civil society is to function liberatingly and inclusively - a space where citizens are educated in democratic dialogue - it is important that its activities are not limited to an autonomous sector. What is crucial here is how the civil society organizations involve the citizens in relation to each other and how these organizations are in dialogue with the other spheres of society. How is the dialogue carried out between civil society organizations on the one hand, and welfare institutions and local authorities as well as private market organizations on the other? In clarifying this question, it is interesting to keep 
in mind that Tocqueville did not explicitly speak of civil society as a delimited sector, but rather argued that a healthy democracy depended on decentralized local decision-making forums, which could be both civilian and political or financial institutions. What interested him was not whether the citizens were active within or outside the individual spheres of society, but rather that they were not passive subjects but active decision-makers in the management of the institutions of society, whether these were political, economic or social (Lichterman and Eliasoph 2014).

In most of the research on civil actions and associational activities, the focus is on volunteers and how they can contribute to democratic skills and inclusiveness, 'bridging' the social differences in Western societies, as noted by Putnam $(1993,2000)$. This is far from what happens in most voluntary organizations, however. Research on volunteering and civil organizations reveals cases where volunteers are recruited to conduct social work, but do not have any influence on how to organize the work. It is a staff of paid professionals who control the organizations, while the volunteers are allocated to practical social work - if there are any volunteers involved in the activities at all. The lack of democracy in numerous civil society organizations has two reasons. One concerns the increased professionalization of social work done by the civil organizations. The commissioners, whether public or private, make increasingly specific demands of the civil organizations, demands that a flexible and fluctuating group of volunteers have difficulties in fulfilling. The second reason is that a growing number of civil organizations have a very limited number of active volunteers. Professionals run the organizations, and 'members' pay their annual fee but have no personal contact with nor influence on the organization and its activities.

From a democratic perspective, it is problematic that an increasing number of civil organizations have only a limited number of members and are run by paid professional labour, while 'members' only contribute with donations and fees, but are not actively involved in the organizations' daily work and management. However, a large proportion of these organizations and institutions can still be considered as part of civil society. Non-profit organizations that produce the public good based on the principles of universality and transparency may be civilian. The conditions are that their activities are civilian and understood as democratic, that they respond to citizens' wishes and needs, and that they contribute to the 'common good' of society.

Instead of polarity between the societal spheres, hybrid forms of collaboration are emerging. This new type of network is important for understanding the liberating and inclusive potential of civil actions. Such networks mix voluntary engagement with public accountability, solidarity and equality in the other social spheres: government, business and local communities (Dekker 2009: 234). We are here talking about organizations and communities that manage to 
build a bridge between the individual and the collective. It is in such organizations, wherever they may be established, that we find the potential for change as well as the liberating and inclusive elements of civilian activities. Civil actions can thus be part of or integrated in all sectors: in relation to service providers, socio-economic enterprises, corporate social responsibility (CSR) principles in for-profit companies, networks in local communities, informal self-help groups, and so on.

What we can see is that the boundaries that have traditionally existed between civil society and the other spheres of society - the state, the market sphere and the private sphere - are being broken down, and that civilian activities are increasingly included in cooperative relations in all spheres of society. It can sometimes be difficult to distinguish between civil society and the state, at least in the area of welfare services. Civilian engagement through volunteer work, community activities, and so on, is seen as an integral part of citizenship and of crucial importance for the inclusion of individuals in the community (von Essen et al. 2015; Enjolras and Sivesind 2009; Enjolras et al. 2018).

\section{Civil Sphere: Conditions for Dialogue and Civility}

The essential thing about the civil sphere - and a fundamental requirement in this context - must be that citizens, through participation in the civil organizations and institutions, are brought together with people from different social groups and from different genders, classes, social backgrounds and religious affiliations. Through these social relations it is possible for citizens to develop trust in each other and to enter into dialogue with those with different views, who they may oppose but with whom they can still agree. It is important for the cohesion of society that consensus is created through dialogue and that there is acceptance of conflicting views. Through these dialogues and mutual recognition, the idea is that citizens can expand their network to influence the political agenda and hold political bodies accountable for their commitments. This must be done at the same time as citizens have the opportunity to participate in the political decision-making process and the implementation of rules and regulations, through being organized in networks and organizations. There are many suggestions for how this influence from civil society organizations can take shape. The way the civil sphere can make a difference in relation to the market sphere, the state sphere and the private sphere could be based on the following principles:

- The creation of social networks and the development of collectivism through active participation on equal terms in all types of organizations. 
- The creation of solidarity between the civil and other social spheres, and the development of skills for being active and participating in the democratic system.

- The establishment of an institutional framework to control power relations and monitor the exercise of authority by public institutions.

- The improvement of the quality and efficiency of citizens' representation by ensuring equal representation based on gender, class, religion and ethnicity.

- The promotion of domination-free dialogue and consensus in the public sphere.

- Ensuring that individual citizens and groups of citizens have access to participation in the economic and political decision-making processes concerning the organization of their living conditions, now and in the future.

\section{CITIZENSHIP}

Citizenship is an active and inclusive concept that confers economic, social and political rights, and makes individuals full members of a society to which they feel a sense of belonging. This understanding of citizenship is based on two central dimensions: active participation in democratic decision-making at all levels, and equal access for all to the resources available in the society. These rights are only one side of the coin. Citizens also have duties - such as funding public services via taxation, respecting the law and playing an active part in democratic dialogue - which represent examples of exhibiting civility. Under these conditions, citizenship provides individuals, irrespective of their social group, with membership of collective, reciprocal social relations and shared values, all of which make it possible to practise citizenship in a post-modern welfare society (Delanty 2000; Isin 2009).

Citizenship, with its rights and duties, is not a static concept. We continuously renegotiate it through participation and dialogue in social networks and organizations, by dint of which people have a say in the future shape of their society. We practice citizenship in our everyday life in the form of a continuous, lifelong process of negotiation and renegotiation of the rights and duties citizens have and practise in their day-to-day lives. The struggle for lived citizenship involves active participation in the workplace, in civil society organizations, in the private sphere, and in the public sphere in the form of political campaigns, demonstrations and civil action. This may sound like a highly idealized interpretation of the concept of citizenship and the conditions for it, and critical questions are often posed about how realistic it is to expect individuals to be able to exert influence on the rights and duties accorded to them by citizenship. 


\section{Active versus Activist Citizenship}

This book defines practising citizenship as the acts and actions through which citizens intervene in political decision-making processes. They may do so for their own individual benefit or to secure rights for social groups otherwise excluded from the established norm for citizenship and the rights associated with it. Acts of citizenship involve both constitutive and disruptive moments; and 'we cannot define acts of citizenship as already inherently exclusive or inclusive, homogenizing or diversifying, or positive or negative. These qualities arise after or, more appropriately, through the act' (Isin 2008: 38). It is important to distinguish between 'active citizens' and 'activist citizens'. 'While activist citizens engage in writing scripts and creating the scene, active citizens follow scripts and participate in scenes that are already created. While activist citizens are creative, active citizens are not' (ibid.).

An 'active citizen' is a person who helps society to function as well as possible as it stands, but in no way seeks to alter any of the existing social structures. This contrasts with what this book defines as 'activist citizens', who combine individual commitment with social and political actions that challenge existing social structures and create the necessary collective frameworks and solidarity to make social change. Activist citizens seek to achieve economic equality through the redistribution of resources, the recognition of differences based on gender, ethnicity, age and sexual orientation, and a more balanced representation of all sections of the population in democratic institutions.

In debates about active citizenship, it is often argued that social changes should be brought about by greater stakeholder involvement, in private companies, public bodies and voluntary organizations. This might solve social and cultural problems by democratizing public institutions and providing greater freedom of choice in relation to welfare institutions. However, these forms of active participation do not change the nature of society's structures. Nor do they necessarily lead to greater equality between social groups. Only when citizenship is used to challenge existing structures and norms for the distribution of economic, social, political and cultural assets - to the extent that the current situation is unfair - is it possible to talk about an activist citizenship and the individual being able to exercise 'the act of claiming citizenship' (Isin 2007).

Given the increasing integration between civil society and the welfare state in recent decades, several social scientists have questioned whether institutionalized civil society has any democratic and emancipatory potential at all (Dekker 2009). It has been posited that the democratic, inclusive and liberating dynamics in society are instead to be found in the overlap between civil society organizations and state or private institutions, or in the looser organizational forms that emerge from networks created via social media. 


\section{PARTICIPATION: CITIZENSHIP AND DEMOCRACY}

Democracy and the activities related to it are closely linked with organizations in the civil sphere, in the same way as membership of associations and participation in their activities are a basic condition for democracy. The right to band together in associations is a key element of political citizenship, and this makes it an important part of schooling in democratic principles, procedures and rules:

The acts of citizenship display freedom in their enactment, they appear through the speech and actions of individuals, and that appearance attains a worldly reality in a public realm where equal and plural individuals also appear (through words and deeds): Equality and diversity are the essential elements of a public realm where acts of citizenship can appear. (Bonner 2008: 148)

It is through associations and organizations in the civil sphere that interpersonal dialogue is established. It is in these contexts that confrontations arise and consensus is reached between conflicting views. It is also here that citizens' wishes and interests are articulated and transformed into political demands. These organizations should be fundamentally democratic, and participation in them voluntary. This means that they too play an important role in the development of a democratic culture. By participating in them, people acquire the skills that are important for engaging in the democratic process and for being active or activist citizens.

One of the crucial challenges facing all liberal democracies in their aspiration for social cohesion and solidarity is how to provide the conditions for people to be active, participative citizens. In other words, how to provide opportunities and frameworks for individuals to commit to social and cultural relationships, and for society and the social collective to show solidarity with disadvantaged groups. Activist citizenship in this context is seen as an important prerequisite for people assuming greater responsibility for their own lives, but also for banding together to assume responsibility for the social collective by taking part in decision-making on key issues in the local community: schools, leisure, health services, planning, and so on.

An open democratic process is, of course, a prerequisite for political decision-making, but it is equally important that organizations in the civil sphere are themselves democratic and participatory, and represent the views of all relevant citizens affected by the policy concerned. Where that is the case, forums for dialogue and communication channels need to be set up so that citizens and their organizations always have the opportunity to question the way social and economic institutions operate and to whom they apply. According to Nancy Fraser (2010), distribution of social and economic resources and 
recognition of diversity are not enough to guarantee social justice. Criteria must also be set for who counts as members of society, and which society is being referred to in the modern, globalized world. With this in mind, Frazer found it necessary to introduce a third dimension - political representation as a prerequisite for citizenship and as a guarantee for equal participation for all citizens in the affairs of society. This political representation is predicated on an active, participatory citizenship and on all members of society being included in social networks and having the opportunity to participate on equal terms in the political governance of society's organizations.

It is in the context outlined above that the many and diverse organizations in the civil sphere can play a central role. They have the potential to ensure that the democratic decision-making process involves all social groups, including vulnerable ones, in both the development and implementation of decisions on welfare policy. Neither market nor state institutions, as these two spheres are currently constituted, can do this, but it should be possible by developing democratic and inclusive organizations at the interfaces between civil society and other spheres of society. The core of the interrelationship between state and civil society is, then, the degree of democratic control and collective engagement within individual organizations, whether public or private. In this respect, it is plausible to talk about state institutions operating on civil society's terms, provided that citizens are in charge of the decision-making and that the structures are democratic, built from the bottom up, and involve the target groups for the institutions' work.

\section{Civil Organizations and Civic Actions: Different Alternatives}

Civil society organizations can play a crucial role in this democratic process, both as mediators of people's wishes and demands concerning welfare policy, and by demanding the inclusion of disadvantaged, less powerful groups and individuals in the social sphere and ensuring that they have a political voice. In this way, civil organizations represent the collective responsibility and act as a counter to the dominant individualism of the age. However, this is only possible if they involve, and thus represent, all of the different groups of citizens, not just the integrated and most politically articulate citizens. To make this possible, the organizations and society as a whole must adhere to the principle of equal participation. In a range of key areas, this requires that the state guarantees a more equitable distribution of resources, and also that forms of social and political participation are created that are liberating and to which there is equal access for all members of society (Fraser 2005, 2007, 2010).

There are apparently a number of contradictory movements taking place in the political public sphere. The background is a growing scepticism among people - inded, a lack of trust - of the established political institutions. We 
find this mistrust manifested in low and declining voter turnout in democratic elections, a sharp decline in the number of citizens who are members of a political party, low confidence in political institutions and a crisis of representative democracy. This crisis has long been under way. The political institutions have become still more hierarchical and bureaucratic, politics is practiced in narrow circles without contact with ordinary people, and the democratic decision-making processes are highly centralized. All these tendencies are exacerbated by globalization, which has led to more and more decisions moving outside the control of national parliaments and politicians.

The development has initiated several reactions. On the one hand, the traditional political establishment has shown considerable interest and an unrealistic belief in the traditional civil society and its organizations. They hope that civil society organizations - and with them, the active citizens - can supplement (and in an increasing number of cases take over) the welfare obligations that the state institutions are not able to manage. This initiative is taken partly because the economic basis for the welfare state is rapidly declining, and partly because social problems are becoming increasingly differentiated and thus more difficult to solve through the existing universal welfare schemes. Here, the political system hopes for help from civil society organizations, which are much more entrenched and have better insight into the problems and wishes of groups of citizens in the differentiated private sphere.

On the other hand, the lack of trust in the established political system has initiated a tremendous boom in political organizations that, outside the established institutions, speak directly to 'the people'. These organizations and social movements base their policies and arguments on an opposition between 'the people' and the elite: those who control the political-administrative system with its powers. This mobilization of people takes place on both the left and the right of the political spectrum, but with extremely different types of organization and actions. Both the left-wing activist organizations and the right-wing populist movements oppose globalization, inappropriate crisis management and increased inequality. There the similarities end.

Unlike the populists, the activist movements campaign for social justice, transparent decision-making processes at all political levels and a directly participatory democracy. In this context, it is important to emphasize the crucial difference between the right-wing populist movements and the left-wing grassroots movements. The populist parties typically have an extremely centralized organization and are often characterized by a vertical construction and charismatic leaders who decide and act without democratic dialogue from or the involvement of the ordinary members - if they are membership organizations at all. Their dialogue with citizens typically takes place via the electronic media and in the form of one-way communication at mass meetings. This is diametrically opposed to the grassroots activist networks, which are strictly 
organized horizontally and in which the citizens concerned are involved in all kinds and at all levels of the decision processes. Here, we are talking about activists who do not rely on the representative democratic system but demand real, direct, active democracy. This means that a democratic decision-making process is established in which all citizens participate on equal terms and with equal access to social and economic resources and the relevant information.

However, left-wing activists demand changes not only in the 'official' political system and its decision-making procedures, but also in the constitution of the existing social movements. Demands for participatory and liberating involvement are thus directed inwards in relation to the way in which the social movements and civil society organizations are functioning. The demand in this context is that within these organizations, the dialogue and activities must be organized based on equal and participatory democratic processes. Numerous studies show that traditional civil society organizations cultivate a notion that they are inclusive and democratic. This holds true for only a few civil society organizations, and the majority are actually segregating and selective in the sense that they differentiate on the basis of age, class, gender, race and religion (Theiss-Morse and Hibbing 2005; Dekker 2009; Eliasoph 2014).

\section{ABOUT BEING AN ACTIVIST CITIZEN: NEW FORMS OF ORGANIZATION}

The core principles of civil society are the active participation of the citizens, critical dialogue and liberating communication in the public sphere. It is important here to make clear what the starting point and conditions for participation are. Most civil activities take place on the premises of the system. There are clear and narrow limitations for these types of activity. Participation in various forms of protest movements obviously has a meaning. It marks a resistance to the system and concrete political actions, but it rarely challenges the basic structures of power. If you want structural and institutional changes in the social structure, and to develop democracy with real content, it is necessary to start from the bottom up: to get the individual citizens, the local community and the civil organizations involved. Only through such an approach can we create forms of government at local as well as national and global levels that represent the people in all their various forms. Such a participatory democracy will not be realized automatically, but will be developed in constant struggle, through conflicts, and must be constantly monitored. Without an insistence on equality of resources and a requirement to recognize diversity, it will not be possible to achieve the liberating participation - emancipation and empowerment - that is necessary to ensure 'parity of participation'.

The growth of bottom-up, grassroots civil institutions all over Europe in the last decade is a clear indication that large groups of people wish to demonstrate 
their independence from public institutions on the one hand, and on the other to be involved in - and in the best case scenario achieve control over - the implementation of governmental policies. Some of the civil institutions that have emerged during these fights are markedly different from traditional civil society in terms of participation, the formal nature of the organizations and, in particular, the way decisions are made within them.

Being a citizen in a participatory and equal democracy makes sense in relation to having civilian obligations. It obliges the individual as well as the collective to participate actively and contribute to the community's development of the public goods for the 'common good'. However, it is important to point out that not all forms of participation and dialogue are democratic, tolerant and supportive. Much of the communication that takes place today in the public sphere is limiting, exclusive and selective. The starting point for the renewal of political culture through the creation of a real or participatory democratic system must consider crucial demands, such as:

- That everyone has a voice on equal terms. It is not enough just to listen to proposals and complaints. People also have to be included in the dialogue and in the decision-making process.

- That all citizens' wishes, dreams and ideas are taken into account in the decision-making process, and that all views are respected in the process of establishing consensus. It is also important that decisions are respected and implemented.

- That all citizens assume the obligation to take part in community affairs. We are talking here about creating a framework for the community that can ensure that the individual, with their special wishes and dreams, has a place in the collective that is being established. We must be able to live differently, and at the same time be a collective (Ishkanian and Glasius 2016).

Participating in demonstrations and various forms of non-conventional, but legal, political protests obviously helps to strengthen morale among groups in opposition to those in power. It gives a sense of power, solidarity and commitment; but without some form of formalized network and civil organizational set-up, it will fade away. It is necessary to develop effective forms of resistance. This may be in the shape of activist networks or autonomous organizations, where individual involvement is combined with social and political actions that attack the existing structures of society and create the necessary collective framework for societal change. Social actions will typically have a lasting impact on the societal structures only if they are backed up by established civil organizations. Through activist and critical participation, the citizen can oppose certain policies, but long-term changes in the existing social structure demand continuous resistance. For example, to ensure eco- 
nomic equality through the redistribution of resources and the recognition of differences based on gender, ethnicity, age and sexual orientation, as well as to introduce a more equal representation of all society's social groups in the democratic institutions, demands long and intense political fights to achieve these goals.

Over the past decade, we have seen increasing demands for influence and inclusive activities in the civil sphere, combined with the emergence of grassroots organized political movements in various political areas. This has contributed to the introduction of changed organizational forms in the mobilization of both civilian activities and political resistance to the crisis management of the established political system.

Although vertical organization has been dominant in virtually all areas - within the private market economy, in the political system and in the organization of civilian activities - significant changes have taken place, especially since the financial crisis of 2008. The hierarchical form of organization with associative membership and decision-making based on representative boards has changed radically, with a move towards horizontally organized basic democratic social movements. These organizations are characterized by that fact that citizens, through social networks and mutual dialogue, have an influence on the prioritization of political goals, are involved in the political decision-making processes and contribute directly to the implementation of decisions. There are many examples of this type of civic political mobilization. Supporters of the Podemos party in Spain are organized into local 'circles', which continuously discuss the movement's political priorities and elect representatives at all levels of the movement. Thus, hundreds of thousands of citizens are active in the election of Podemos's general secretary and leadership. Another example of this kind of horizontally organized social movement is Citizens UK, which organized political actions regarding the mayoral election in London with the participation of local civic groups, and coordinated the work of defining political demands for the city council. These forms of organization have long existed within the syndicalist and anarchist movements. With the growing distrust of the existing representative political system, and its inefficiency in solving the economic and social problems of ordinary citizens, these active and inclusive forms of participation have become increasingly popular.

All these social movements have a loose organizational structure. The basic organizational unit is local networks, which are partly in dialogue with each other and partly coordinated in connection with the actions and political initiatives that are taken by the movement. The prerequisite for the establishment of the loose, changeable structures within these organizations, where members and sympathizers can be activated at short notice, has been the spread of social media. This makes it easy to be in constant communication, make 
quick decisions, and practice a basic democracy where key decisions within the organization can be put out for debate and decision-making among all of the movement's activists. So far, the perception has been that social media is primarily used for communication and information dissemination. However, it has also been shown that a combination of online and offline communication is a very effective tool, both in the development of lasting social networks and in terms of creating a developed and robust active participatory and inclusive organizational decision-making system that can ensure that all people with an interest can become involved. 